\title{
RHINOLOGY
}

\section{Treatment of congenital nasolacrimal duct cyst: the role of endoscopic marsupialisation}

\author{
II trattamento delle cisti congenite del dotto nasolacrimale: \\ il ruolo della marsupializzazione endoscopica
}

\author{
Vittorio Rampinelli ${ }^{1}$, Marco Ferrari ${ }^{1,2}$, Silvia Zorzi ${ }^{1}$, Marco Berlucchi ${ }^{3}$ \\ ${ }^{1}$ Unit of Otorhinolaryngology-Head and Neck Surgery, University of Brescia, ASST Spedali Civili of Brescia, Italy; ${ }^{2}$ Section \\ of Otorhinolaryngology-Head and Neck Surgery, Department of Neurosciences; University of Padua, Italy; ${ }^{3}$ Unit of Pediatric \\ Otorhinolaryngology, ASST Spedali Civili of Brescia, Italy
}

\begin{abstract}
SUMMARY
Objective. Congenital nasolacrimal duct cyst (NLDC) is a rare disorder, which can present with ophthalmological and nasal signs and symptoms. The authors analyse their personal experience to identify diagnostic criteria for NLDC, which were treated by endoscopic transnasal procedure.

Methods. Clinical records of patients with a diagnosis of NLDC were retrospectively reviewed. All patients underwent rhinoscopy and ophthalmologist evaluation before surgery, whereas imaging was performed in selected cases. All neonates underwent transnasal endoscopic marsupialisation after failure of conservative medical therapy.

Results. Five patients were included in the study. One patient presented bilateral NLDC. In 3 cases, CT scan of the sinus was carried out. A total of 6 marsupialisation procedures were performed and a bi-canalicular lacrimal stent was positioned in 1 case. Complete remission of symptoms was observed in all cases.

Conclusions. Nasal endoscopy is mandatory to diagnose NLDCs, and, in some cases, it can be complemented by radiological procedures. When symptoms persist after systemic and topical therapy, nasal endoscopic marsupialisation is the treatment of choice. This surgical procedure is effective, safe and can be repeated if needed.
\end{abstract}

KEY WORDS: nasolacrimal duct, children, nasal surgical procedures, minimally invasive surgical procedures

\section{RIASSUNTO}

Obiettivo. La cisti congenita del dotto nasolacrimale (CDNL) è una condizione rara, che si manifesta con segni e sintomi oftalmologici e nasali. Gli autori analizzano la propria esperienza al fine di identificare criteri diagnostici per la CDNL, trattata con procedura endoscopica transnasale (ET).

Metodi. È stata eseguita un'analisi retrospettiva dei dati clinici dei pazienti affetti da CDNL. I pazienti sono stati sottoposti ad endoscopia nasale (EN) e valutazione oculistica prima dell'intervento, l'imaging è stato eseguito in casi selezionati. Tutti i neonati sono stati sottoposti a marsupializzazione ET dopo fallimento di terapia medica.

Risultati. Cinque pazienti sono stati inclusi nello studio. Un paziente ha presentato CDNL bilaterale. In 3 casi, è stata eseguita TC del massiccio facciale. Sono state eseguite 6 procedure di marsupializzazione; uno stent lacrimale bi-canalicolare è stato posizionato in 1 caso. La remissione completa dei sintomi è avvenuta in tutti i casi.

Conclusioni. L'EN è chiave per la diagnosi di CDNL e può essere integrata con procedure radiologiche. Quando i sintomi persistono dopo terapia sistemica e topica, la marsupializzazione ET rappresenta il trattamento di scelta. Questa procedura chirurgica è efficace, sicura e può essere se necessario ripetuta.

PAROLE CHIAVE: dotto nasolacrimale, pediatrico, procedure chirurgiche nasali, procedure chirurgiche mininvasive
Received: March 23, 2020

Accepted: May 21, 2020

\section{Correspondence}

Vittorio Rampinelli

Unit of Otorhinolaryngology-Head and Neck Surgery, Department of Medical and Surgical Specialties, Radiological Sciences, and Public Health, University of Brescia, ASST Spedali Civili di Brescia, 25121 Brescia, Italy

Tel. +39030 3995319. Fax +390303995212

E-mail: vittorio.rampinelli@gmail.com

Funding

None.

Conflict of interest

The Authors declare no conflict of interest.

How to cite this article: Rampinelli V, Ferrari M, Zorzi S, et al. Treatment of congenital nasolacrimal duct cyst: the role of endoscopic marsupialisation. Acta Otorhinolaryngol Ital 2020;40:377382. https://doi.org/10.14639/0392-100X-N0759

(C) Società Italiana di Otorinolaringoiatria e Chirurgia Cervico-Facciale

\section{(c) (1) (3) $(-)$}

This is an open access article distributed in accordance with the CC-BY-NC-ND (Creative Commons Attribution-NonCommercial-NoDerivatives 4.0 International) license. The article can be used by giving appropriate credit and mentioning the license, but only for non-commercial purposes and only in the original version. For further information: https:// creativecommons.org/licenses/by-nc-nd/4.0/deed.en 


\section{Introduction}

Congenital nasolacrimal duct (NLD) obstruction is a common disorder. Cassady reported incomplete canalisation of NLD in more than $70 \%$ of newborns ${ }^{1}$, with Hasner's valve being the most frequent site of stenosis ${ }^{2,3}$. The majority of cases resolve spontaneously during the first weeks of life ${ }^{4,5}$, while persistent epiphora is observed in 6-20\% of infants 5,6 . Several malformations have been attributed to persistent epiphora in young patients. The term "inferior mucocele" or "NLD cyst" (NLDC) refers to an unperforated Hasner's valve showing an inferior prolapse and therefore occupying the inferior meatus and nasal cavity ${ }^{7}$. NLDC associated with dacryocystocele, which consists of a cystic enlargement of lacrimal sac ${ }^{8}$, is reported in $0.1 \%$ of infants during the first year of life ${ }^{5}$. The dacryocystocele may resolve spontaneously, but frequently becomes infected and rapidly progresses to acute dacryocystitis, lacrimal sac empyema and preseptal/orbital cellulitis ${ }^{9}$.

Diagnosis of NLDC is usually based on clinical symptoms, endoscopic appearance and imaging. The typical clinical presentation includes epiphora, history of relapsing dacryocystitis, and unilateral nasal obstruction. When the malformation is bilateral, clinical presentation emulates adenoid hypertrophy, with different respiratory issues consisting of chronic snoring respiration, difficulties in sleeping and feeding, and severe respiratory distress associated with cyanosis and/or intercostal retraction. At nasal endoscopic evaluation, NLDC appears as a mucosal translucent protrusion stemming from the inferior meatus, in proximity to the area of Hasner's valve. If associated with dacryocystocele, a blue swelling at the level of the ipsilateral medial cantus is usually noticeable. CT scan of the sinuses confirms diagnosis, above all when the nasal fossa is not clearly explorable and/or other associated conditions are suspected ${ }^{10}$.

Management of NLDC includes conservative and nonconservative treatments. The former comprises massage of the lacrimal sac, topical antibiotics and steroids and systemic antibiotic therapy. The latter, which usually follows an unsuccessful conservative strategy, consists of a surgical procedure, ranging from nasolacrimal probing to intranasal endoscopic marsupialisation ${ }^{2}$. The aim of the present single-institution study is to analyse clinical outcomes of children who underwent transnasal endoscopic marsupialisation of NLDC and to identify clinical and endoscopic diagnostic criteria to diagnose congenital NLDC.

\section{Materials and methods}

Patients and preoperative workup

Clinical records of patients who underwent transnasal endoscopic marsupialisation of a NLDC at the Unit of
Pediatric Otorhinolaryngology, Spedali Civili of Brescia, Brescia - Italy, from January 2010 to January 2019 were retrospectively reviewed.

Informed consent was systematically acquired at time of hospitalisation. Ethical approval was not required due to the retrospective nature of the study and anonymisation of all data.

All patients underwent preoperative flexible nasal endoscopy and ophthalmologist evaluation. Before January 2013, all patients underwent CT scan of sinuses to confirm diagnosis; thereafter, our diagnostic strategy changed, in order to avoid redundant radiological exams. We utilised the following diagnostic criteria for NLDC:

- nasal obstruction;

- epiphora;

- nasal endoscopy revealing a translucent, cystic lesion centered on the anterior portion of the inferior turbinate and obstructing the nasal fossa;

- no suspicion of orbital complications at ophthalmologist evaluation;

- no suspicion of another pathological condition (i.e., choanal atresia, pyriform aperture stenosis, nasopharyngeal teratoma, and meningoencephalocele) at flexible nasal endoscopy.

If all the above criteria were satisfied, a clinical diagnosis was made and CT and/or magnetic resonance imaging (MRI) were deemed unnecessary. All patients underwent surgery after failure of conservative treatments (i.e., massage of the medial cantus, antibiotic and steroid eye drops, systemic antibiotic therapy) for at least 3 weeks. Signs of acute inflammation of the nasolacrimal duct system were considered a temporary contraindication to surgery, which was postponed after resolution of inflammation-related symptoms.

\section{Surgical technique and postoperative management}

The surgical procedure was performed under general anaesthesia. After mucosal decongestion with pledgets soaked with adrenalin $(1: 100,000)$, a rigid nasal $0^{\circ}$ endoscope 2.7 diameter, $11 \mathrm{~cm}$ long (Karl Storz, Tuttlingen, Germany) connected with high definition camera and xenon-175-watt cold light illumination source (HD 3 CCD camera, Karl Storz, Tuttlingen, Germany) was placed intranasally to identify and analyze the extent of NLDC. The NLDC was marsupialised by removing the anteromedial wall of the cyst by cold sharp instruments that are commonly employed for otosurgery. In one case, a microdebrider was used to perform partial marsupialisation of NLDC. Once valve patency was checked with a $30^{\circ}$ scope (Karl Storz, Tuttlingen, Germany), antibiotic ointment (Mupirocin) was applied in the inferior meatus. Bilateral NLDCs were oper- 
Table I. Relevant data of the present series (Pt: patient; CT: computed tomography; DCC: dacryocystocele).

\begin{tabular}{lccccccc} 
Patient & $\begin{array}{c}\text { Age/ } \\
\text { Gender }\end{array}$ & $\begin{array}{c}\text { Unilateral/ } \\
\text { bilateral }\end{array}$ & Imaging & $\begin{array}{c}\text { Associated } \\
\text { findings }\end{array}$ & $\begin{array}{c}\text { Breastfeeding } \\
\text { difficulties }\end{array}$ & $\begin{array}{c}\text { Breathing } \\
\text { difficulties }\end{array}$ & Hospitalisation days \\
1 & 5 months/F & Unilateral & CT & DCC & No & No & 3 \\
2 & 18 days/M & Unilateral & CT & None & No & No & 2 \\
3 & 12 days/F & Unilateral & CT & None & Yes & No & 2 \\
4 & 45 days/F & Bilateral & No & None & Yes & No & 2 \\
5 & 2 months/M & Unilateral & No & None & No & No & 1 \\
\hline
\end{tabular}

ated on concurrently with a bilateral procedure. No nasal packing was applied after surgery.

Patients underwent systemic antibiotic therapy (amoxicillin) for 1 week and nasal irrigation twice per day for 1 month after surgery. The first postoperative outpatient control with nasal flexible endoscopy was scheduled at 1 week. Patients were closely followed for 3 months after surgery, until appropriate healing of the surgical site was endoscopically demonstrated. The last control was scheduled at 12 months after surgery. According to Lueder ${ }^{9}$, the procedure was considered successful if both symptoms and signs attributable to lacrimal obstruction or inflammation completely recovered.

\section{Results}

Five patients were included in the study. Transnasal endoscopic marsupialisation of the NLDC was the primary surgical treatment for all patients. Relevant data of the series are summarised in Table I. Two patients were male and 3 were females, with a mean age of 26 days (range: 12 days to 4 months). All children had normal development with no other relevant comorbidities. No case of acute respiratory distress was observed. In all patients, ophthalmologic evaluation documented the presence of epiphora associated with at least one episode of dacryocystitis, presenting with eyelid oedema and purulent secretions from lacrimal canaliculi. Medial canthal swelling was observed in 1 patient, who had a concomitant dacryocystocele.

Nasal endoscopy showed a cystic lesion centered on the area of Hasner's valve in all patients. The cyst filled the inferior meatus and nasal fossa, occluding the ipsilateral nasal respiratory space (Fig. 1). The middle meatus was usually patent or partially narrowed due to cranial displacement of the inferior turbinate.

CT scan of sinuses was performed in the 3 cases treated before January 2013, showing an enlarged NLD that was in continuity with a cystic lesion within the nasal cavity. In all these cases, the NLDC was occupied by hypodense material and hypertrophy of soft tissues of the medial or-

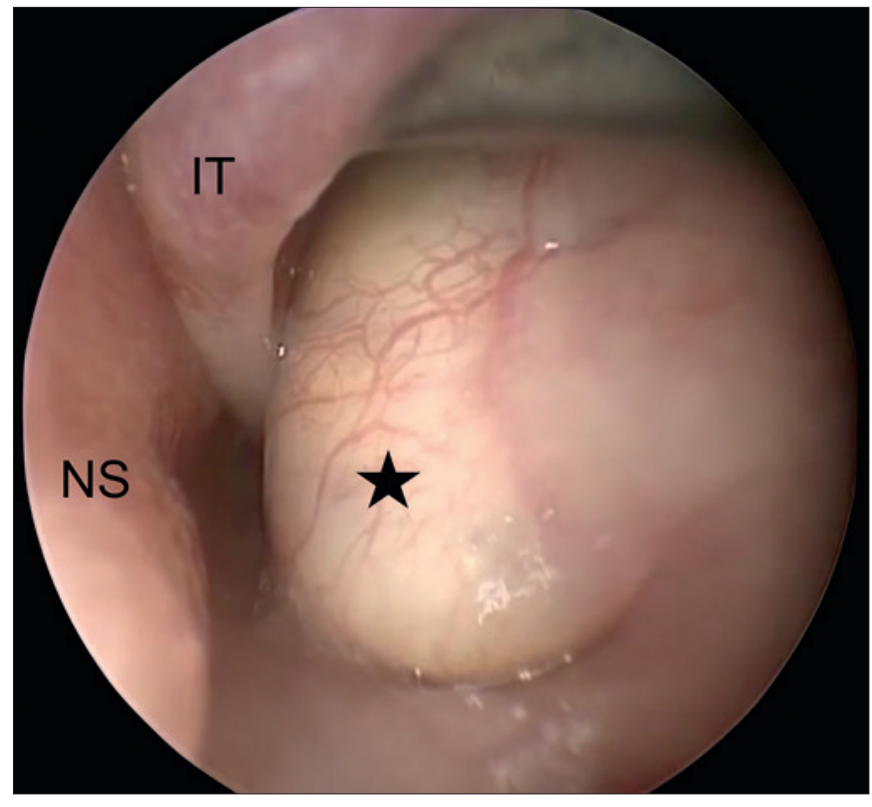

Figure 1. Endoscopic appearance of congenital nasolacrimal duct cyst (asterisk) in left nasal fossa. Inferior turbinate (IT) is displaced laterally and superiorly. NS - Nasal septum.

bital canthus was observed. A concomitant dacryocystocele was identified in a single case. No other malformations or associated conditions were detected.

Following the abovementioned diagnostic criteria, 2 cases were treated based on clinical and endoscopic diagnosis after January 2013.

Six endoscopic marsupialisation procedures were performed (4 unilateral and 1 bilateral surgeries). Intraoperative probing of the nasolacrimal system was avoided. In the patient with a dacryocystocele, a bi-canalicular lacrimal stent was positioned and removed 6 months later under general anaesthesia.

No perioperative complication was observed. All patients were discharged within the first and third postoperative day. Endoscopic outpatient medications and follow-up evaluations were performed at 1 week, and 1, 2, 3, and 12 months after surgery. Simple local anaesthesia without se- 
dation was employed during outpatient evaluation. Complete recovery of symptoms was observed in all patients.

\section{Discussion}

The present retrospective observational study reviewed 5 patients undergoing endoscopic transnasal marsupialisation for NLDC at a single institution between 2010 and 2019. The aim of the study was to identify clinical and endoscopic features that allow diagnosis of NLDC. Moreover, an overview of the management strategy for this exceedingly rare clinical entity, focusing on postoperative results of endoscopic treatment, was performed. To the best of our knowledge, only a few case reports or limited case series on the transnasal endoscopic marsupialisation of NLDC can be found in the literature. Moreover, some of confusion has emerged around this pathological entity, especially concerning its distinction from similar diseases such as dacryocystocele.

The pathogenesis of both NLDC and dacryocystocele consists of mucosal obstruction of the NLD, which leads to increasing pressure and subsequent dilatation of the lacrimal system in areas that are not completely surrounded by bone (i.e. Hasner's valve and the lacrimal sac, respectively). The level of obstruction on a craniocaudal axis determines whether the cystic swelling appears as a dacryocystocele or a NLDC: cysts located in proximity to Hasner's valve exhibit an intranasal cystic mass with possible retrograde dilation of the NLD, while more cranial obstruction does not show relevant nasal changes ${ }^{11}$.

Infantile dacryocystocele and many cases of paediatric acute dacryocystitis are associated with NLDC ${ }^{9}$. Barham et al. ${ }^{4}$ even hypothesised that the coexistence of the two entities (dacryocystocele and NLDC) is unvarying. On the other hand, many cases of NLDCs are not associated with a congenital dacryocystocele, nor to epiphora or other disturbances referable to the lacrimal $\mathrm{sac}^{2,12}$. In the present series, which includes 4 monolateral and 1 bilateral NLDCs, all patients experienced at least 1 episode of acute dacryocystitis, whereas a dacryocystocele was present in a single case. The slight female predisposition reported by Levin et al. ${ }^{13}$ and Brachlow et al. ${ }^{14}$ was confirmed in our series, with a male-to-female ratio of 2:3.

Diagnosis is based on history, clinical examination and nasal endoscopy: nasal obstruction, epiphora, medial canthal swelling, eyelid oedema and purulent secretions from lacrimal canaliculi are the most frequent clues, with nasal endoscopy revealing a translucent, cystic lesion centered on the anterior portion of the inferior turbinate and obstructing the nasal fossa. As bilateral NLDCs can be associated with complete nasal obstruction and severe respiratory distress, although never ob- served in our series, anterior rhinoscopic examination should be included in routine newborn examination, especially when newborns or neonates present obstructive symptoms ${ }^{14}$.

The lacrimal system connects the orbital and nasal complexes; therefore, multidisciplinary management of its pathological conditions is recommended. Hence, all patients in our series underwent ophthalmologist evaluation to exclude proximal stenosis, orbital complications, or other malformations. The role of imaging in diagnostic work-up is ill-defined. CT and dacryocystographic findings of patients affected by dacryocystocele and NLDCs have been described by several authors ${ }^{15,16}$. The presence of a cystic lesion of the anterior-inferior-lateral portion of the lateral nasal wall, medial displacement of the inferior turbinate, and pronounced distention of NLD possibly associated with lacrimal sac dilation are the main signs raising suspicion for NLDC. Castillo et al. ${ }^{16}$ diagnosed NLDC using CT to evaluate 2 newborns who presented with acute respiratory distress immediately after birth. Both were found to have bilateral soft-tissue masses beneath the inferior turbinates. MRI has also been used in evaluation of dacryocystoceles ${ }^{17}$, by virtue of its optimal contrast resolution on soft tissue, which allows characterisation of the cyst content. The primary advantage of MRI over CT is the avoidance of exposure to ionising radiation. On the other hand, MRI requires sedation of the newborn and provides poorer depiction of bony surfaces.

We performed CT scan in the first 3 cases we handled to study the anatomical region and confirm diagnosis. Based on our experience and the literature ${ }^{2}$, we thought that clinical and endoscopic evaluation could be sufficient for diagnosis. Thus, after January 2013, we introduced clinical diagnostic criteria in our practice. If satisfied, an exclusively clinical diagnosis was deemed reliable to proceed with treatment, and imaging was avoided. Unfortunately, the small number of patients due to rarity of the disease does not permit to perform statistical analysis. Consequently, we hope that present study could stimulate a multicentre trial that confirms this hypothesis.

However, CT and/or MRI should be considered to corroborate diagnosis when the nasal fossa is not clearly explorable or other/associated conditions are suspected: choanal atresia, pyriform aperture stenosis, nasopharyngeal teratoma and meningoencephalocele ${ }^{2,10}$.

Sundry treatment approaches have been described for management of NLDCs: massage, warm compresses, topic, enteral or parenteral antibiotics, nasolacrimal probing, laser mucosal vaporisation, silastic stenting, and intranasal endoscopic cyst marsupialisation. Our management consisted first of medical therapy associated with delicate massage of the medial canthus. If these therapeutic procedures failed, transnasal endoscopic marsupialisation of the cyst was performed. 
Though limited to a small sample size, endoscopic transnasal marsupialisation showed optimal results in the present series: all 5 patients, for a total of 6 procedures, experienced complete remission of symptoms after surgery, in line with what reported in the literature ${ }^{2,9,13,18}$. Some authors have suggested probing the NLD to verify its patency after marsupialisation ${ }^{2,18}$. In our experience, lavage of the lacrimal pathway is sufficient to demonstrate the patency of NLD. With the intent of avoiding inflammation-related complications, an endoscopic procedure was performed when signs of acute inflammation resolved with medical therapy. However, other authors highlighted that in cases of acute infection resistant to antibiotic therapy prompt surgical management should be considered to prevent disease progression ${ }^{9}$. In line with Natesh et al. ${ }^{7}$, we consider the use of powered instrumentation (e.g. microdebrider) a wise option to achieve sharp and precise dissection of the cyst. During resection of redundant mucosa, attention should be paid to avoid injury of Hasner's valve and the inferior turbinate, which could lead to nasolacrimal air reflux and excessive scar tissue formation, respectively.

Some authors have used prolonged silicone stenting of the NLD to prevent recurrence after marsupialisation of the cyst ${ }^{19,20}$. We positioned a bi-canalicular lacrimal stent in only the first patient we treated. In subsequent cases, we chose to avoid canal stenting, further reducing the invasiveness of the procedure ${ }^{2,9}$. However, lacrimal stenting could be considered in patients with bone/mucosal malformations associated with NLDC and recurrent disease.

Postoperative meticulous management, including nasal irrigations and repeated endoscopic medications, was probably the key of the overall success of treatment. Of note, the anterior position of the surgical wound allowed avoidance of sedation during medications, otherwise required for endoscopic posterior procedures in non-cooperating patients. Recently, bedside nasal endoscopy with cyst marsupialisation under local anaesthesia have been proposed as an effective primary treatment option ${ }^{21,22}$. Although feasibility of this procedure is witnessed by these publications, this management strategy should be taken into consideration in specific conditions, including stable patients, favourable nasal anatomy and an expert medical team.

The main limitations of the present study consist of its retrospective nature and limited sample size. Considering the rarity of NLDC, a multicentre, prospective study would be useful to better elucidate issues that are not reliably inferable on the basis of small case series.

\section{Conclusions}

NLDC is a rare disease to be included in the differential diagnosis of nasal obstruction associated with epiphora in newborns and infants. Multidisciplinary management by both an otorhinolaryngologist and ophthalmologist is recommended. The suggestive clinical picture associated with a complete nasal endoscopy could be sufficient for diagnosis. On the other hand, cross-sectional imaging should be considered in case of uncertain diagnosis or suspect for concomitant malformations. Our experience, even if limited to 5 NLDC cases, suggests that endoscopic marsupialisation without NLD stenting is an effective and safe procedure. However, a multicentre, prospective study is needed to establish whether this treatment is significantly preferable over other surgical techniques alongside more precisely quantify the morbidity of surgery.

\section{References}

1 Cassady JV. Developmental anatomy of nasolacrimal duct. AMA Arch Ophthalmol 1952;47:141-58. https://doi.org/10.1001/archopht.1952.01700030146003

2 Dogan E, YükseL NG, Ecevit MC, et al. Microdebrider assisted endoscopic marsupialization of congenital intranasal nasolacrimal duct cysts. Int J Pediatr Otorhinolaryngol 2012;76:488-91. https://doi. org/10.1016/j.ijporl.2011.12.031

3 Bansal S, Gupta AK. Endoscopic management of pediatric nasolacrimal anomalies. Clin Rhinol An Int 2014;7:16-9. https://doi. org/10.1016/j.otc.2006.07.004

4 Barham HP, Wudel JM, Enzenauer RW, et al. Congenital nasolacrimal duct cyst/dacryocystocele: An argument for a genetic basis. Allergy Rhinol (Providence) 2012;3:e46-49. https://doi.org/10.2500/ ar.2012.3.0024

5 MacEwen CJ, Young JD. Epiphora during the first year of life. Eye (Lond) 1991;5:596-600. https://doi.org/10.1038/eye.1991.103

6 Guerry D 3rd, Kendig EL Jr. Congenital impatency of the nasolacrimal duct. Arch Ophthal 1948;39:193-204. https://doi.org/10.1001/ archopht.1948.00900020198006

7 Natesh BG, Patil S, Nilssen E, et al. Endonasal microdebrider assisted excision of congenital intranasal nasolacrimal duct cyst or inferior mucocele. Indian J Otolaryngol Head Neck Surg 2016;68:115-7. https://doi.org/10.1007/s12070-015-0948-y

8 Harris GJ, DiClementi D. Congenital dacryocystocele. Arch Ophthalmol 1982;100:1763-5. https://doi.org/10.1001/archopht.1982.01030040743006

9 Lueder GT. The association of neonatal dacryocystoceles and infantile dacryocystitis with nasolacrimal duct cysts (an American Ophthalmological Society thesis). Trans Am Ophthalmol Soc 2012;110:74-93.

10 Calcaterra VE, Annino DJ, Carter BL, et al. Congenital nasolacrimal duct cysts with nasal obstruction. Otolaryngol Head Neck Surg 1995;113:481-4. https://doi.org/10.1016/s0194-5998(95)70090-0

11 Mansour AM, Cheng KP, Munna JV, et al. Congenital dacryocele. A collaborative review. Ophthalmology 1991;98:1744-51. https://doi. org/10.1016/s0161-6420(91)32063-3

12 Righi PD, Hubbell RN, Lawlor PP Jr. Respiratory distress associated with bilateral nasolacrimal duct cysts. Int J Pediatr Otorhinolaryngol 1993;26:199-203. https://doi.org/10.1016/0165-5876(93)90028-2

13 Levin AV, Wygnanski-Jaffe T, Forte V, et al. Nasal endoscopy in the treatment of congenital lacrimal sac mucoceles. Int J Pediatr Otorhinolaryngol 2003;67:255-61. https://doi.org/10.1016/s01655876(02)00379-8 
14 Brachlow A, Schwartz RH, Bahadori RS. Intranasal mucocele of the nasolacrimal duct: an important cause of neonatal nasal obstruction. Clin Pediatr (Phila) 2004;43:479-81. https://doi. org/10.1177/000992280404300511

15 Raflo GT, Horton JA, Sprinkle PM. An unusual intranasal anomaly of the lacrimal drainage system. Ophthalmic Surg 1982;1:741-4.

16 Castillo M, Merten DF, Weissler MC. Bilateral nasolacrimal duct mucocele, a rare cause of respiratory distress: CT findings in two newborns. AJNR Am J Neuroradiol 1993;14:1011-3.

17 Brugger PC, Weber M, Prayer D. Magnetic resonance imaging of the fetal efferent lacrimal pathways. Eur Radiol 2010;20:1965-73. https:// doi.org/10.1007/s00330-010-1755-1

18 Shashy RG, Durairaj VD, Holmes JM, et al. Congenital dacryocystocele associated with intranasal cysts: diagnosis and management. Laryngoscope 2003;11:37-40. https://doi.org/10.1097/00005537200301000-00007
19 Teixeira CC, Dias RJ, Falcão-Reis FM, et al. Congenital dacryocystocele with intranasal extension. Eur J Ophthalmol 2005;15:126-8. https://doi.org/10.5301/EJO.2008.4834

20 Grin TR, Mertz JS, Stass-Isern M. Congenital nasolacrimal duct cysts in dacryocystocele. Ophthalmology 1991;98:1238-42. https://doi. org/10.1016/s0161-6420(91)32149-3

21 Suzuki Y, Omura K, Otori N, et al. Endonasal marsupialisation of a congenital intranasal nasolacrimal duct cyst. BMJ Case Rep 2019;12:e228284. https://doi.org/10.1136/bcr-2018-228284

22 Zhao NW, Chan DK. Awake bedside nasal endoscopy for primary management of neonatal dacryocystoceles with intranasal cysts. Int J Pediatr Otorhinolaryngol 2019;123:93-6. https://doi.org/10.1016/j. ijporl.2019.04.043 